\title{
ANÁLISIS Y COMENTARIO A LA STS DE 2 DE JULIO 2018 SOBRE LA IMPUGNACIÓN INDIVIDUAL DE DESPIDO PRODUCIDO EN EL MARCO DE DESPIDO COLECTIVO FINALIZADO CON ACUERDO
}

\author{
Christian Navarro Díaz \\ Abogado en ejercicio y profesor de Derecho del Trabajo en la Escuela de Práctica \\ Jurídica del Ilustre Colegio de la Abogacía de Barcelona, y profesor de Derecho del \\ Trabajo de la Universidad Oberta de Catalunya
}

\begin{abstract}
Análisis de la doctrina del Tribunal Supremo sobre el alcance de la impugnación individual de despido producido en el marco de un despido colectivo finalizado con acuerdo; y concretamente de la reciente sentencia de dos de julio de 2018.

Analysis of the Supreme Court's doctrine about the scope of the individual impugnation of termination of contract as a result of an agreement reached in a collective dismissal procedure, and concretely analysis of the recent sentence of July 2, 2018.
\end{abstract}

Title: Analysis and comments of the decision of the Supreme Court of July $2^{\text {nd }}, 2018$ regarding individual impugnation of the dismissal in the context of a collective dismissal that ended with an agreement

Palabras clave: despido colectivo, impugnación de la causa, acción colectiva, acción individual, doctrina del valor reforzado.

Keywords: collective dismissal, impugnation of the cause of termination, collective action, individual action, reinforced value doctrine.

IUSLabor 3/2018, ISSN 1699-2938, pp. 263-275

DOI. 10.31009/IUSLabor.2018.103.09

\section{Sumario}

1. Introducción

2. Resumen del pronunciamiento contenido en la sentencia 2 de julio de 2018

2.1. El Supuesto de hecho analizado

2.2. Argumentos argüidos en el voto mayoritario

2.3. Argumentos del voto minoritario

3. Comentario crítico 


\section{Introducción}

¿Está legitimado un trabajador para impugnar individualmente las causas de su despido cuando dicho despido se ha producido en el marco de un despido colectivo finalizado con acuerdo entre el empresario y la representación de los trabajadores?

Ésta es la cuestión que resuelve la Sentencia no 699/2018, dictada por el Pleno de Sala Cuarta del Tribunal Supremo el 2 de julio 2018 (Recurso no 2250/2016), siendo que, ya lo anticipamos, el voto mayoritario de cinco magistrados resuelve en sentido negativo, declarando la falta de legitimación de los trabajadores para impugnar, por el cauce individual, las causas del despido colectivo cuando el período de consultas finaliza con acuerdo; con la excepción de que el acuerdo se haya subscrito concurriendo fraude, dolo, coacción o abuso de derecho.

Por su parte, el voto particular de los restantes cuatro magistrados del pleno aboga por la solución inversa y permitir, como se venía haciendo hasta la fecha, dicha impugnación causal también en el procedimiento individual de despido.

Las soluciones del voto mayoritario y voto particular se encuentran en las antípodas, por lo que el principio del tercio excluso obliga al estudio de ambas posiciones para clarificar cuanto menos sus fundamentos y justificaciones.

Así, el presente estudio tiene por objeto: i) analizar la citada STS 2 de julio de 2018 para centrar el foco de la discusión y establecer el marco argumental tanto del voto mayoritario, como del voto particular; y ii) realizar un comentario crítico respecto a la solución adoptada por la Sala, centrándonos en algunos argumentos no tratados en el voto particular y que, quizá, podrían haber variado el sentido del voto.

\section{Resumen del pronunciamiento contenido en la sentencia 2 de julio de 2018}

La doctrina judicial y el Tribunal Supremo venían admitiendo la posibilidad de impugnar la causa de un despido colectivo mediante el procedimiento individual, aún cuando el periodo de consultas hubiera finalizado con acuerdo. No obstante, a partir de la modificación del artículo 124.11 de la Ley 36/2011, de 10 de octubre, reguladora de la jurisdicción social (en adelante LRJS) los Juzgados y Salas del orden Social inician un peregrinaje de sentencias contradictorias que han venido a culminar en la STS 2 de julio de 2018 .

En efecto, el artículo 11 del Real Decreto Ley 11/2013, de 2 de agosto, da un nuevo redactado al artículo 124.11.a) LRJS, eliminando su segundo párrafo referente a la 
necesidad de demandar a los representantes de los trabajadores cuando el despido se hubiera acordado con ellos, siempre que el despido no hubiera sido impugnado colectivamente por la parte disidente del acuerdo, caso de haberla. ${ }^{1}$

Con anterioridad a esta modificación normativa el Tribunal Supremo había establecido que el alcance que en el proceso individual debía atribuirse al acuerdo alcanzado en el período de consultas de un despido colectivo era el de "valor reforzado", lo que no vetaba la impugnación de la causa por el cauce individual, si bien incrementaba la carga de alegación y prueba del demandante.

Frente a este criterio, el Tribunal Supremo revisa su posición y declara la imposibilidad de revisar en el pleito individual la concurrencia de las causas del despido colectivo aceptadas en el acuerdo firmado por la representación de los trabajadores, equiparando el régimen de impugnación individual del acuerdo al propio de los supuestos contemplados en los artículos 40, 41, 47 y 82 del Real Decreto Legislativo 2/2015, de 23 de octubre, por el que se aprueba el texto refundido de la Ley del Estatuto de los Trabajadores (en adelante ET), y recordando que el límite de la negociación colectiva se encuentra en la afectación a derechos indisponibles de los trabajadores, así como a la eventualidad de que se hubiere concertado dicho acuerdo con elusión de normas legales de derecho necesario. Así, se mantiene la teoría del valor reforzado, pero ahora ya solo se aplica a la hora de resolver la impugnación, legítima, que pudieran haber formulado los representantes sindicales o unitarios minoritarios que no suscribieron el acuerdo.

\subsection{El Supuesto de hecho analizado}

\footnotetext{
${ }^{1}$ El párrafo suprimido por el artículo 11 RDL 11/2.013 establecía textualmente: “Igualmente deberán ser demandados los representantes de los trabajadores cuando la medida cuente con la conformidad de aquéllos, siempre que no se haya impugnado la decisión extintiva, de acuerdo con lo previsto en los aparatados anteriores, por los representantes de los trabajadores no firmantes del acuerdo".

2 Doctrina del valor reforzado, por todas SSTS/IV 25/6/2.014 (RCO 165/2.013) y 24/2/2.015 (RCO 165/2.014), en las que se establece que: “debemos llamar la atención sobre el hecho de que la decisión extintiva del empresario... cuenta con la aceptación de una cualificada (más de dos tercios) mayoría de la representación social en la Comisión Negociadora de despido colectivo. La existencia de este acuerdo no significa ni que ello implique una presunción de que concurren las causas justificativas de los despidos, ni que la decisión empresarial de proceder a dichos despidos no pueda impugnarse sin tratar de invalidar previamente o, al menos, simultáneamente... el acuerdo por fraude, dolo, coacción o abuso de derecho, puesto que tales previsiones -contenidas en el artículo 47.1 del ET respecto de las suspensiones de contratos de trabajo derivadas de causas económicas, técnicas, organizativas o de producción- no figuran ni en el artículo 51 del ET ni en el artículo 124 de la en relación con los despidos por las mismas causas. Ahora bien, sentado esto, no es menos cierto que el juzgador podrá tener en cuenta, a la hora de apreciar la efectiva concurrencia de las causas justificadoras de los despidos alegadas por la empresa, el hecho, muy significativo, de que los representantes de los trabajadores -en este caso, el 77\% de los integrantes del banco social de la comisión negociadora- han considerado que, efectivamente, dichas causas justificadoras concurrían en el supuesto de autos".
} 
La Sala analiza el caso de un despido colectivo producido en la escuela de música y danza del Ayuntamiento de Ciempozuelos, Madrid.

El 16 de mayo 2.013 se subscribió acta final del período de consultas con acuerdo. En dicha Acta se establece que los trabajadores afectados por el despido percibirían una indemnización equivalente a treinta y tres días de salario por cada año de servicio, con un máximo de dieciocho mensualidades. En dicha Acta se concretó el salario de cada uno de los trabajadores y la indemnización específica que correspondía a cada trabajador.

La Inspección de trabajo emitió informe de 24 de mayo 2.013 indicando que no apreciaba indicios de fraude, dolo, coacción o abuso de derecho en la consecución del acuerdo.

Diez trabajadores disconformes con su despido impugnaron judicialmente su extinción previa la pertinente reclamación administrativa.

El Juzgado Social desestimó la demanda en instancia. Recurrida la sentencia, el Tribunal Superior de Justicia de Madrid desestimó el recurso de suplicación instado por los trabajadores.

Alzado en casación para la unificación de doctrina, y una vez admitido a trámite el Recurso, el Ministerio Fiscal emite informe en el que considera que el recurso debe ser estimado.

El recurso de Casación para la Unificación de doctrina gira en torno a dos cuestiones: la primera atiende al alcance que en el proceso individual de despido debe atribuirse al pacto entre empresario y representación de los trabajadores sobre la concurrencia de la causa justificativa del despido.

La segunda cuestión versa sobre el posible incumplimiento de los requisitos formales derivados de la falta de concreción de las causas motivadoras del despido colectivo en la carta de notificación individual a los trabajadores. ${ }^{3}$

\subsection{Argumentos argüidos en el voto mayoritario}

\footnotetext{
${ }^{3}$ El presente estudio únicamente abarca la primera de las cuestiones planteadas en el recurso por establecer, a nuestro entender un cambio jurisprudencial relevante.
} 
El voto mayoritario aduce los argumentos que, de manera sistemática y agrupados por grupos, se indican:

a) Interpretación sistemática y finalista de la normativa sustantiva y procesal:

- Ausencia de previsión expresa que habilite a discutir la concurrencia de causa en los pleitos individuales cuando el período de consultas finaliza con acuerdo.

- Eliminación del segundo párrafo de la letra a) del artículo 124.13 LRJS.

- Integración sistemática del artículo 51 ET con los artículos 41, 47 y 82 ET, que sí contienen una previsión expresa que imposibilita dicha revisión causal en el procedimiento individual.

- Integración y lógica unitaria con la regulación establecida en la Ley 22/2.003, de 9 de julio, Concursal (en adelante Ley Concursal o LC) -artículo 64-, que impone al juez del concurso la obligación de aceptar el acuerdo que pudiere haberse alcanzado con la representación de los trabajadores, imposibilitando la revisión de la causa en los incidentes individuales de impugnación.

b) Afectación a la tutela judicial de la empresa:

- La empresa no podría interponer acción de jactancia si el período de consultas finaliza con acuerdo. ${ }^{4}$

- Legítima pretensión de la empresa de zanjar con el acuerdo la polémica sobre la efectiva concurrencia de las causas justificativas del despido colectivo.

- Inexistencia de procedimiento colectivo impugnatorio donde se pueda resolver de manera uniforme y en un único procedimiento la concurrencia de la causa, con efecto de cosa juzgada sobre los eventuales litigios individuales que pudieran plantearse.

c) Objeto y finalidad de la consulta:

- El art 51.2 ET impone la obligación a las partes de "negociar de buena fe, con vistas a la consecución de un acuerdo".

- El régimen jurídico establecido para las materias contempladas en los artículos 41, 47, 82 y 51 ET se sustenta sobre dos pilares:

- Incentivar y fomentar la consecución de acuerdo entre empresa y trabajadores.

- Atribuir eficacia de litispendencia y cosa juzgada al proceso colectivo frente al individual, con carácter general en el artículo 160.3 LRJS, y específicamente para el despido colectivo, en el artículo 124 LRJS.

\footnotetext{
${ }^{4}$ En este sentido STS 26/12/13: no es admisible "la existencia de un proceso de impugnación colectiva del despido si no existe un sujeto colectivo que se oponga al despido y esté en condiciones de hacerlo efectivamente en el proceso".
} 
d) Separación funcional de los ámbitos colectivo e individual:

- Diferente régimen jurídico para las acciones colectivas e individuales, derivando al proceso colectivo la discusión sobre la concurrencia de la causa, y reservando al proceso individual el análisis de las cuestiones particulares.

- El sistema descansa en la consideración de que en el proceso individual únicamente cabe abordar las cuestiones estrictamente atinentes singularmente a cada uno de los trabajadores demandantes.

e) Seguridad jurídica e igualdad de trato:

- Evitación de la litigiosidad, siendo que la exposición de motivos del RDL 11/2.013 establece dicha finalidad. $^{5}$

- Inseguridad jurídica y efecto distorsionador que puede generar la existencia de innumerables procesos individuales en los que se estuviese discutiendo la concurrencia de la causa de un mismo despido colectivo de una misma empresa, cuando ha concluido con acuerdo.

- Posible saturación de los órganos jurisdiccionales del orden social.

- Ausencia de respuesta homogénea perseguida por el legislador.

\subsection{Argumentos del voto minoritario}

Por su parte, el voto minoritario se sustenta sobre los siguientes argumentos:

a) Interpretación de la normativa sustantiva y procesal:

- No existe previsión expresa que restrinja la posibilidad de discutir la causa alegada en el procedimiento individual, aunque haya finalizado con acuerdo.

- Esa falta de restricción es coherente con la remisión que el artículo 124.13 LRJS realiza, con algunas especialidades, a las reglas sobre impugnación individual de despido, donde no aparece la imposibilidad de revisar si concurre la causa invocada para extinguir el contrato.

- Establece el artículo 124.13.a) LRJS, entre otras cosas, que podrá ser considerado nulo el despido "cuando el empresario no haya realizado el período de consultas o

\footnotetext{
${ }^{5}$ El RDL 11/2.013 establece en su exposición de motivos: "se justifica la necesidad de introducir mejoras técnicas en la nueva modalidad procesal de despidos colectivos (...) para evitar la litigiosidad y la saturación de los órganos jurisdiccionales del orden social, cumplir con el principio de celeridad consagrado legalmente y proporcionar una mayor seguridad jurídica".
} 
entregado la documentación prevista en el artículo 51.2 ET"; con ello se está admitiendo que las cuestiones de dimensión colectiva o general también pueden cuestionarse en el procedimiento individual si previamente no ha habido control judicial.

- La regulación del despido colectivo en el ámbito concursal (artículo 64 LC) no debería utilizarse como criterio interpretativo, y ello por cuanto:

- La Ley Concursal es anterior a la regulación del despido colectivo introducida en $2.012^{6}$, siendo que cuando se promulga la LC el despido colectivo regulado en el artículo 51 ET estaba sujeto a autorización administrativa, y en caso de acuerdo la autoridad laboral debía dictar resolución en el plazo de quince días naturales, entendiéndose autorizada la medida si no hubiese recaído resolución expresa en dicho plazo.

- Tanto en la LC como en el ET de 2003 la adopción de la medida depende de un tercero imparcial, el juez del concurso en el primer caso, y la autoridad laboral en el segundo. No es el caso del procedimiento regulado en el artículo 51 ET.

- La regulación contenida en el artículo 64 LC no ha seguido las transformaciones experimentadas por el ET.

- En el despido concursal el juez acepta el acuerdo salvo que aprecie la existencia de fraude, dolo, coacción o abuso de derecho, por lo que el juez debe examinar si dicho acuerdo adolece de alguno de estos vicios. Por el contrario, en el despido colectivo establecido en el artículo 51.2 y 4 ET, el acuerdo alcanzado despliega todos sus efectos, y aunque debe comunicarse el contenido del acuerdo a la autoridad laboral, la eficacia de tal acuerdo no se supedita a la decisión de la autoridad laboral.

- Las enormes diferencias entre ambas regulaciones (artículo 64 LC y 51 ET) impiden que la primera pueda resultar indicativa de la voluntad del legislador de dar un tratamiento uniforme a todas las situaciones colectiva, tales como las previstas en los artículos 40, 41, 47 y 82.3 ET.

b) Tutela judicial efectiva:

- La imposibilidad de trasladar al órgano jurisdiccional los acuerdos, decisiones o conductas no es acorde al Estado de Derecho (artículo 1.1 CE) y al control efectivo de la decisión empresarial (STC 8/2015, 22 enero), cuando estamos ante un conflicto jurídico.

- Impedir la revisión judicial de la concurrencia de la causa del despido colectivo podría comportar una limitación al derecho a la tutela judicial efectiva (artículo 24 $\mathrm{CE})$.

\footnotetext{
${ }^{6} \mathrm{La}$ introducción de la nueva regulación del despido colectivo se realiza con la reforma de 2012: RDL 3/2012, de 10 de febrero, y Ley 3/2012, de 6 de julio.
} 
- La defensa de la tutela judicial del empleador no puede conducir a la negación de similar derecho a quien ha venido trabajando bajo su dependencia; a tal efecto se apuntan algunas soluciones para conjugar ambos derechos:

- Reconsiderar la doctrina limitativa de la 'acción de jactancia' por parte de la empresa y posibilitarla en los casos en que exista acuerdo en el periodo de consultas.

- Conferir al acuerdo alcanzado en el período de consultas el "valor reforzado" tal como se venía aplicando, obligando a quien sostuviera la inexistencia de la causa o su insuficiencia probar los fundamentos de su pretensión.

- Activar la virtualidad procesal de las procedimientos o sentencias previas sobre el asunto. (litispendencia, acumulación de procesos, cosa juzgada)

c) Surgimiento de una atípica 'cosa juzgada'

- Aceptar la imposibilidad impugnatoria supone asumir que el acuerdo alcanzado posea el mismo valor que la sentencia judicial, pues el efecto práctico de tal acuerdo será un valor similar al de cosa juzgada que impide cuestionar la concurrencia de la causa habilitante en el pleito individual.

d) Naturaleza del pacto en el período de consultas de un despido colectivo.

- Dicho pacto es un verdadero acuerdo colectivo que posee regulación específica dada su singularidad; sin que existan motivos para no poder ser impugnado individualmente del mismo modo que puede ser impugnado un convenio colectivo individualmente. (Impugnación indirecta; artículo 163.4 LRJS).

e) Control causal del despido colectivo

- La presunción iuris tantum de concurrencia de las causas cuando se alcanza pacto en los procedimientos previstos en los artículos 40, 41, 47 y 82.3 ET no puede aplicarse a los procedimientos de despido colectivo puesto que requiere un control causal por parte de los órganos judiciales.

- Posible infraprotección del derecho al trabajo (artículo 35.1 CE) si no se permite la revisión judicial de la causa alegada.

\section{Comentario crítico}

Partiendo de un gran respeto por la sentencia en general, y por los votos en ella contenida, en particular, se echan de menos algunos razonamientos que podrían, creemos, haber variado el sentido del voto mayoritario. 
- Tutela Judicial Efectiva e interpretación conforme a los Tratados Internacionales. Convenio 158 de la OIT sobre terminación del contrato de Trabajo. La causalidad del despido y su obligado control por organismo neutral como derecho atribuido de modo individual al trabajador.

Consideramos, en primer lugar, que la posibilidad del trabajador de ejercitar una acción para revisar las causas de su despido es una cuestión íntimamente relacionada con un derecho fundamental, cual es el de acceder a un proceso con las debidas garantías y obtener una tutela judicial efectiva. Se trata, por tanto, de una materia en la que no se puede imponer una interpretación restrictiva ni, mucho menos aún, contraria a los tratados internacionales suscritos por España. De hecho, conforme al artículo 10.2 de la Constitución, dicho derecho fundamental debe interpretarse necesariamente de conformidad con los tratados y acuerdos ratificados por España, que por imperativo del artículo 96.1 del mismo texto Constitucional se integran directamente en el ordenamiento jurídico tras su ratificación.

Además, con la entrada en vigor de la Ley 25/2.014, de 27 de noviembre, de tratados y otros acuerdos internacionales, se ha desarrollado completamente las previsiones establecidas en el artículo 96.1 CE. De este modo se deja claramente afirmada la aplicación directa de los tratados internacionales válidamente celebrados y publicados en el Boletín Oficial del Estado ${ }^{7}$, e igualmente llano es que el legislador, así como el juzgador, deben respetar las obligaciones de los tratados internacionales y velar por su adecuado cumplimiento, tal como mandata el artículo 29 de la precitada ley.

Sentado esto, creemos que se debe tomar en consideración el Convenio número 158 de la Organización Internacional del Trabajo, sobre la terminación de la relación de trabajo, de 22 de junio 1.982, en tanto que del mismo se deriva tanto el principio de causalidad y de justificación necesaria y suficiente del despido, como el derecho del trabajador de recurrir contra la misma ante un organismo neutral ${ }^{8}$.

El artículo 8 del citado convenio atribuye de forma muy clara y precisa el derecho de recurso al trabajador, y no a los sujetos colectivos de representación, al establecer que: "[e]l trabajador que considere injustificada la terminación de su contrato de trabajo tendrá derecho a recurrir contra la misma ante un organismo neutral, como un tribunal, un tribunal de trabajo, una junta de arbitraje o un árbitro. 8.2 Si una

\footnotetext{
7 Artículos 28 a 31 de la Ley 25/2.014, de 27 de noviembre, de Tratados y otros Acuerdos Internacionales.

${ }^{8}$ Artículos 4, 9.1, 9.2 del Convenio número 158 sobre la terminación de la relación laboral de trabajo, de la OIT.
} 
autoridad competente ha autorizado la terminación, la aplicación del párrafo 1 del presente artículo podrá variar de conformidad con la legislación y la práctica nacionales".

Del propio modo se establece en su artículo 9.1 y 3 que los organismos de revisión de la decisión extintiva "estarán facultados para examinar las causas invocadas para justificar la terminación y todas las demás circunstancias relacionadas con el caso, y para pronunciarse sobre si la terminación estaba justificadas", así como que, en caso de tratarse de causas objetivas, los organismos de revisión "estarán facultados para verificar si la terminación se debió realmente a tales razones, pero la medida en que esos organismos estarán facultados también para decidir si esas razones son suficientes para justificar la terminación deberá determinarse por los métodos de aplicación mencionados en el artículo 1 de este Convenio."

De esta normativa se deduce claramente que la atribución de la acción de revisión del despido y sus causas se atribuye de modo individual y personal al trabajador afectado, y no a terceros o a sujetos de representación colectiva, siendo que esta atribución de una acción judicial debe considerarse una manifestación del derecho fundamental a la Tutela Judicial Efectiva, sobre la que no cabría hacer interpretaciones restrictivas, ni cubrir silencios legislativos de modo desfavorable al principio "pro actione" como, a nuestro entender, ha hecho el voto mayoritario de la Sentencia que estamos analizando.

Y es que las dudas que pueda suscitar el último inciso del artículo 9.3 del Convenio, relativo a la posibilidad de atenuar el alcance de la revisión judicial en relación con la suficiencia de las causas en casos de despido colectivo -que no a la constatación de su existencia que deberá ser posible en todo caso-, se resuelven directamente al constatar que no existe ninguna disposición interna que se haya adoptado con el objetivo de desarrollar esta concreta facultad excepcional, siendo que, como ya hemos dicho, ante el silencio del legislador que debería desarrollar o adaptar las normas del tratado como modo de aplicación preferente previsto en el artículo 1 del mismo Convenio, no cabe sostener una interpretación que restrinja el derecho fundamental atribuido individualmente al trabajador.

Con todo, queda claro que la acción de revisión que el Convenio atribuye de modo individual al trabajador no puede quedar limitada, ni tan siquiera por la legislación nacional, cuando se dirige a verificar si la terminación se debió a las razones invocadas por la empresa, cosa que a nuestro juicio resulta incompatible con el veto a la impugnación de las causas en la acción individual de despido colectivo tramitado con acuerdo con la representación de los trabajadores. 
Por otro lado, la específica previsión el artículo 8.2 del Convenio relativa a si ha intervenido o no una autoridad competente que autorice la extinción, da una explicación lógica y razonable del establecimiento de una regulación diferente en la Ley Concursal en relación con el Estatuto de los Trabajadores, en tanto que en dicho procedimiento la extinción es acordada por el Juez, abonando por tanto la interpretación sistemática que hace el voto discrepante de la sentencia aquí analizada.

\section{- Configuración del período de consultas}

Entendemos que hay otra cuestión que justificaba el diferente alcance del acuerdo conseguido en un procedimiento para la adopción de las medidas de reestructuración empresarial ex artículo 40, 41 y el alcanzado en un despido colectivo. Se trata de la diferente regulación del objeto o finalidad del período de consultas establecido para ambos tipos de medida.

Así, vemos que los artículo 40.2, 41.4 ET establecen que el período de consultas "versará sobre las causas motivadoras de la decisión empresarial y la posibilidad de evitar o reducir sus efectos", mientras que el artículo 51.2 ET señala que la consulta “deberá versas, como mínimo, sobre las posibilidades de evitar o reducir los despidos colectivos y atenuar sus consecuencias mediante el recurso a medidas sociales de acompañamiento destinadas, en especial, a la ayuda para la readaptación o la reconversión de los trabajadores despedidos"9.

Esta última regulación es muy llamativa si se toma en consideración que antes de la reforma laboral del año 2012 la regulación del periodo de consultas del despido colectivo sí que establecía que el mismo debía versar sobre las causas del despido. Ello justifica y hace razonable el distinto alcance que cabe atribuir al acuerdo alcanzado en ambos tipos de procesos de consulta. Es razonable y justificado que, en el despido colectivo, al que se aplica un convenio internacional que lo somete al principio de causalidad, se aplique un canon de control judicial más estricto que para medidas menos traumáticas, a los que no se aplica dicho convenio internacional, y para las que la ley ya prevé un control necesario de la causa durante el periodo de consultas.

Siendo claro que en nuestro sistema el despido colectivo debe responder a una causa justificada y suficiente, no debería admitirse una regulación que permita escapar de toda posibilidad de control o valoración de sus causas, como sucede al impedir la impugnación individual del despido colectivo por mor de un acuerdo alcanzado en un

\footnotetext{
${ }^{9}$ Esta concreta previsión legal ha sido traspuesta, de manera literal, ordenamiento español de la Directiva 98/59/CE del Consejo de 20 de julio de 1.998 relativa a la aproximación de las legislaciones de los Estados miembros que se refieren a los despidos colectivos.
} 
periodo de consultas en el que pueden no haberse discutido las causas, y en el que no existe ninguna autoridad neutral que lo autorice. Así, bastaría seducir a la representación social de las bondades de un acuerdo para escapar de todo control causal, y ello pese a no concurrir las obligadas causas de despido, (pensemos en el caso de los períodos de consultas en los que la empresa ofrece altas indemnizaciones -en algunos casos superiores a las indemnizaciones previstas ex artículo 56 ET-alcanzándose acuerdo con la representación de los trabajadores), lo que equivaldría a validar cualquier despido acausal sin más requisito que alcanzar un acuerdo con la representación social.

- El fraude de ley

Por último, y a mayor abundamiento, queremos referir la figura del fraude definida legalmente en el artículo 6.4 del Código Civil.

Si bien el sentido del voto mayoritario no excluye la impugnación individual respecto a las causas cuando el acuerdo colectivo se hubiera alcanzado concurriendo fraude, dolo, coacción, o abuso de derecho, es evidente que la existencia de fraude no podrá probarse a menos que se pueda entrar en la valoración de la causa.

A la luz de la norma internacional precitada y de la doctrina constitucional, podemos advertir que una de las formas de fraude - probablemente la más común y utilizadaconsiste en adoptar una medida extintiva cuando no concurre causa legal aduciendo una causa aparente. En tal caso no estaríamos ante un despido, sino estrictamente ante un desistimiento empresarial, figura proscrita en nuestro ordenamiento tal como hemos visto, si bien con algunas excepciones (véase el desistimiento durante el período de prueba, o su previsión en algunas relaciones laborales especiales).

Imposibilitar la revisión causal en el procedimiento individual podría blindar dicho fraude e incluso avivarlo, por cuanto el acuerdo podría suscribirse ante la apariencia de causa cierta, siendo imposible la acreditación del fraude sin una previa revisión de las causas alegadas. Dicho de otro modo, se antoja prácticamente imposible descubrir el fraude por inexistencia de causa, cuando el período de consultas finalice con acuerdo, puesto que es evidente que la empresa habrá alegado la concurrencia de causa y habrá entregado la documentación reglamentariamente precisa. Ante esta situación, consideramos que la única salida posible es la de posibilitar el examen de la causa para valorar si efectivamente concurre fraude de ley o abuso de derecho, puesto que de no hacerlo se privaría dicho motivo de impugnación de toda efectividad. 
Fecha recepción: 4.12.2018

Fecha aceptación: 24.12.2018 